possibility of transplanting certain species of invertebrates from the Azov to the Caspian. The Ichthyological Research Institute has decided to begin with the transplantation of Nereis, which is able to withstand changes in salinity and temperature and is unaffected by lower contents of oxygen.

\section{Wilhelm Erb}

Prof. Winhelm Heinrich Erb, a pioneer in neuropathology and electrotherapy, was born at Winneweiler in the Palatinate on November 30, 1840. He received his medical education at Heidelberg, where he was assistant to Nikolaus Friedreich, and qualified in 1864. After working with Buhl at Munich on morbid anatomy, he was appointed extraordinary professor of special pathology and treatment at Leipzig in 1867 and full professor in 1880. Three years later he was transferred to the corresponding chair at Heidelberg, where he remained until his retirement in 1917. His first work was in connexion with toxicology, histology and therapeutics, but afterwards he devoted himself almost entirely to neurology. Erb's name, either alone or in association with those of other neurologists such as Duclenne, Charcot and Goldflam, has been given to several nervous diseases. He was also the first to describe the knee-jerk, independently of Westphal, and simultaneously with Fournier demonstrated the close etiological association between syphilis and tabes and general paralysis. $\mathrm{He}$ died on October 29, 1921.

\section{The Night Sky in December}

ON December 22 the sun enters the sign Capricornus (the winter solstice). The night reckoned from sunset to sunrise then lasts $16 t$ hours in the latitude of London. Full moon is on December 14 and new moon on December 28. At meridian passage soon after 0h. on December 15 at Greenwich, the moon's altitude is $57^{\circ}$. Jupiter and Saturn, the conspicuous pair of bright planets, are visible throughout the greater part of the night. On December 11, they are in conjunction with the moon at $1 \mathrm{~h}$. and $6 \mathrm{~h}$. respectively. (All times are given in Universal Time; add $1 \mathrm{~h}$. to convert into Summer Time.) Mars is a morning star rising about half an hour before Venus on December 15. These two planets are in conjunction with one another on December 2 at 12h. On December 25 at $18 \mathrm{~h}$., Mars is in conjunction with the moon, and Venus is likewise in conjunction on December 26 at $18 \mathrm{~h}$. The rapidly changing positions of Jupiter's four inner satellites, their transits and eclipses, may be followed from the data given on p. 630 of the Nautical Almanac or on p. 182 of Whitaker's Almanack. Saturn's unique ring system is well open; a refractor of 2 inches aperture or larger is, however, required to resolve the rings. The bright stars of Perseus, Auriga, Taurus and Orion (with Procyon and Sirius in train), bring glory to the December night skies. There are the open star clusters of Perseus, the Pleiades and the Hyades: many wellknown double stars, variable stars and nebulæ in abundance. Near o Tauri is a dark nebulous region which Barnard considered as giving the strongest proof of the existence of obscuring matter in space. Near the irregular variable star, $T$ Tauri, is the remarkable object known as Hind's variable nebula. Two notable nebulæ, exemplifying two distinct types, are both visible to the naked eye on moonless nights during this month. These are the great nebulæ of Orion and Andromeda-the first a greatly extended diffuse nebula of radiating gas lying within our Milky Way system: the second, a vastly remote stellar system in itself, the prototype of many millions which are shown on long-exposure plates taken with the largest reflecting telescopes. At midnight on December 31-January 1, 1941, Sirius, the brightest star in the heavens, is within 2 minutes of the southern meridian of Greenwich.

\section{Announcements}

DuRING a recent air raid, the Great Hall of the University of Bristol was damaged. The Great Hall is one of a series of magnificent buildings presented to the University by Sir George Wills and Mr. H. H. Wills, in memory of their father, the first Chancellor, and opened by King George V in 1925.

IT is announced in France, the journal for Free Frenchmen published daily in Great Britain, that Prof. P. Langevin, who has just been awarded the Copley Medal of the Royal Society (see NATURE, Nov. 23, p. 679) is now in prison.

Dr. G. Roussy, rector of the University of Paris and formerly dean of the medical faculty and professor of pathological anatomy, and M. Maurice Guyot, general secretary of the University, have been removed by order of the Vichy Government.

DR. D. H. Pracock, professor of chemistry in the University of Rangoon and special chemical adviser (Customs) to the Government of Burma, is retiring from the service of the Government of Burma.

Dr. Donтcho Kostofr, of the Institute of Genetics, Academy of Sciences, U.S.S.R., has been appointed to a position in the Central Agricultural Experiment Station at Sofia, Bulgaria.

Mr. Harold Hartuey has been appointed lecturer in mine surveying in the University of Leeds, in succession to Mr. T. Brown, resigned.

Mrs. J. R. OAden and her family have presented to the Brotherton Library of the University of Leeds a large collection of lantern slides. These, added to the slides given by Mr. Ogden during his lifetime, bring the number in the Collection to more than five thousand. The slides deal largely with Palestine and Egypt, and include more than four hundred slides on the tomb of Tutankhamen.

Ir has been found necessary to close the Museum of the Royal College of Surgeons until further notice. Those who wish to present specimens to the Museum should retain them in their possession, but should notify the Curators of their intention to present them at a later date. 